\title{
Plant Proton Pumps and Cytosolic pH-Homeostasis
}

\author{
Maike Cosse and Thorsten Seidel*
}

Dynamic Cell Imaging, Department of Biochemistry and Physiology of Plants, Faculty of Biology, Bielefeld University, Bielefeld, Germany

Proton pumps create a proton motif force and thus, energize secondary active transport at the plasma nmembrane and endomembranes of the secretory pathway. In the plant cell, the dominant proton pumps are the plasma membrane ATPase, the vacuolar pyrophosphatase (V-PPase), and the vacuolar-type ATPase (V-ATPase). All these pumps act on the cytosolic $\mathrm{pH}$ by pumping protons into the lumen of compartments or into the apoplast. To maintain the typical $\mathrm{pH}$ and thus, the functionality of the cytosol, the activity of the pumps needs to be coordinated and adjusted to the actual needs. The cellular toolbox for a coordinated regulation comprises 14-3-3 proteins, phosphorylation events, ion concentrations, and redox-conditions. This review combines the knowledge on regulation of the different proton pumps and highlights possible coordination mechanisms.

Edited by:

José Antonio Fernández, University of Malaga, Spain

Reviewed by:

Ramón Serrano,

Universitat Politècnica de València,

Spain

Kees Venema,

Consejo Superior de Investigaciones Cientificas (CSIC), Spain

${ }^{*}$ Correspondence:

Thorsten Seidel tseidel@uni-bielefeld.de

Specialty section: This article was submitted to Plant Membrane Traffic and

Transport,

a section of the journal Frontiers in Plant Science

Received: 26 February 2021 Accepted: 15 April 2021

Published: 09 June 2021

Citation:

Cosse M and Seidel T (2021) Plant

Proton Pumps and Cytosolic pH-Homeostasis.

Front. Plant Sci. 12:672873. doi: 10.3389/fpls.2021.672873
Keywords: vacuolar-type ATPase, vacuolar pyrophosphatase, plasma membrane-ATPase, 14-3-3, redox

\section{INTRODUCTION}

Central reactions, such as glycolysis, nitrate reduction, antero-, and retrograde signaling take place in the cytosol, but the cytosol is also a transit compartment for many solutes, which reside transiently in the cytosol subsequent uptake and before compartmentation into organelles. Though the $\mathrm{pH}$ in the cytosol is chemically buffered by bicarbonates, phosphate, and proteins, it is affected by other ions. pH-stat (7.1-7.5) is achieved physically by proton pumps and secondary active transport and chemically by metabolic processes, which either consume or release protons (Schumacher, 2014; Feng et al., 2020). The required pH in compartments and the apoplast might lead to a conflict with cytosolic $\mathrm{pH}$-stat so that proton pumping alone is not sufficient. Then, cytosolic proton-scavenging by malate decarboxylation or glutamate decarboxylation allows for active chemical buffering and compensation for limited proton pumping. However, malate production releases four protons, so that de novo synthesis is counterproductive, while vacuolar malate storage ensures a backup of buffering capacity (Feng et al., 2020; Wegner and Shabala, 2020).

\section{The Plant Plasmamembrane Forms the Barrier to the Apoplast}

The plant plasmamembrane forms the barrier to the apoplast. The apoplastic $\mathrm{pH}$ depends mainly on anion-channels, cation-antiporters, and plasma membrane-ATPase (PM-ATPase; Geilfus, 2017; Mangano et al., 2018). Cation channels like GORK1 co-operate with the PM-ATPase, too (van Kleeff et al., 2018), while opening of Kat1 depends on the apoplastic pH (Kazmierczak et al., 2013). Furthermore, clock-like oscillations were observed which might be connected to reactive oxygen species (ROS)-oscillations (Mangano et al., 2018). 
The pH-buffering capacity of the apoplast is only $10 \%$ of the cytosolic buffering capacity (Wegner and Shabala, 2020). This leads to rapid and transient fluctuations of the apoplastic $\mathrm{pH}$ and membrane potential. Apoplastic $\mathrm{pH}$-alterations comprise both acidification and alkalization: for instance, apoplastic $\mathrm{pH}$ increases in leaves in response to stress factors, such as drought, salinity, and pathogens and might serve as systemic messenger. Alkalization probably involves proton uptake due to inhibition of the PM-ATPase or increased proton permeability. To terminate the signal, the apoplast becomes re-acidified within $2 \mathrm{~h}$, reflecting re-activation of the PM-ATPase (Geilfus, 2017; van Kleeff et al., 2018). On the other hand, apoplastic acidification was observed in response to Fusarium oxysporun. Such pathogeninduced $\mathrm{pH}$-changes regulate the growth defense and have a direct impact on pathogenicity (Kesten et al., 2019). Apoplast alkalinization is essential for growth of pollen tubes and root hairs (Mangano et al., 2018).

The vacuole is the main storage compartment for solutes and contributes up to $90 \%$ of the cellular volume, but the tonoplast contains just $1 \%$ of the cellular proteins, displaying the low abundance of transport protein in the cellular proteome (Fricke, 2017; Martinoia, 2018). Two types of proton pumps dominate at the tonoplast, comprising the vacuolar-type ATPase (V-ATPase) and the vacuolar pyrophosphatase (V-PPase), which energize transport at the tonoplast (Seidel et al., 2013). The acidic conditions in early endosomes (EE) and the trans-Golgi network (TGN) are required for proper transport and sorting. Altered $\mathrm{pH}$ homeostasis in TGN/EE disturbs cargo sorting and trafficking to vacuole by receptor-cargo interactions. Recently, Krebs and co-workers stated that the TGN/EE contributes to the uptake of solutes destined for the vacuole. In this scenario, the V-ATPase acidifies the lumen of the TGN and drives sodiumuptake in case of salinity (Krebs et al., 2010). NHX5 and 6 mediate $\mathrm{K}^{+} / \mathrm{H}^{+}$exchange at the TGN/EE while CLC-d is capable to maintain the $\mathrm{pH}$-gradient, regulating the luminal $\mathrm{pH}$ this way (von der Fecht-Bartenbach et al., 2007; Bassil et al., 2011). The vacuolar isoforms NHX1 and NHX2 serve as cation/proton antiporters (Sze and Chanroj, 2018), but are probably not essential for sodium sequestration (Barragán et al., 2012).

\section{PROTON PUMPS}

The PM-ATPase utilizes ATP as energy source (Wegner and Shabala, 2020) and drives solute uptake and water uptake at the plasmamembrane (Fricke, 2017), thereby having an impact on phloem loading, metabolite transport, and growth and nutrient uptake and distribution (Briskin and Hanson, 1992; Morsomme and Boutry, 2000; Palmgren, 2001; Sondergaard et al., 2004; Zhao et al., 2008). Together with anion channels, the PM-ATPase functions in the re-acidification of the apoplast subsequent alkalization (Geilfus, 2017; Feng et al., 2020), while hyperpolarization is driven by PM-ATPase under acid stress, followed by electrical balancing by potassium symporters and

Abbreviations: V-ATPase, vacuolar-type ATPase; PM-ATPase, plasma membraneATPase; V-PPase, vacuolar pyrophosphatase; NHX, $\mathrm{Na}^{+} / \mathrm{H}^{+}$-antiporter. channels (Sze and Chanroj, 2018). In guard cells, the PM-ATPase is of particular importance, since it is involved in stomatal closure with respect to environmental factors, for instance in pathogen-induced stomatal closure (Kaundal et al., 2017). Eleven isoforms (AHA1-11) of the PM-ATPase are known in Arabidopsis thaliana. Except of AHA10, which was found at the tonoplast in the endothelium, all members locate to the plasma membrane (Appelhagen et al., 2015; Li et al., 2016). The PMF generated by AHA1 and AHA2 is essential and a double knock-out of both turned out to be embryolethal (Mangano et al., 2018; Sze and Chanroj, 2018). In addition to blue-light-dependent activation, AHA2 requires light for proper transport to the plasma membrane and locates to endomembranes with dim light (Haruta et al., 2018). AHA7 senses the apoplastic pH in root epidermal cells via an extracellular loop and represses proton pumping as negative feedback regulation (Hoffmann et al., 2019).

The vacuolar pyrophophatase functions as homodimeric proton pump (Figure 1) at the tonoplast and acidifies in particular vacuoles of expanding cells (Smart et al., 1998; Maeshima, 2001; Segami et al., 2010). It enables the usage of other resources than ATP and increases the cellular energy-use efficiency (Munns et al., 2020), since pyrophosphate is a byproduct of multiple processes, such as protein, starch, and cellulose synthesis (Taiz, 1992). Two types of V-PPases are known, which differ in potassium and calcium sensitivity (Maeshima, 2000). Calcium-inhibition occurs through formation of $\mathrm{CaPP}_{\mathrm{i}}$ as inhibitor or direct binding of $\mathrm{Ca}^{2+}$ as inhibitory ligand (Baykov et al., 1993; Sivula et al., 1999).

AVP1 of A. thaliana belongs to the type I V-PPases, which locate to the vacuole and are nearly $\mathrm{Ca}^{2+}$-insensitive, but potassium-sensitive (Almeida et al., 2017). The type II V-PPase AVP2, which is $\mathrm{Ca}^{2+}$-sensitive and potassium insensitive, was found at the Golgi in A. thaliana (Mitsuda et al., 2001). V-PPases keep the cytosolic pyrophosphate level low and avoid inhibition of gluconeogenesis by high pyrophosphate concentrations (Martinoia, 2018), but hyper activity of V-PPases has negative effects on cellular viability (Graus et al., 2018). During germination, V-PPases are of even higher importance than soluble PPases (Martinoia, 2018). AVP1 further localizes to the plasma membrane in companion cells of sieve elements and was suggested to function as pyrophosphate synthase. This inverse function might maintain the pyrophosphate homeostasis in this cell type and supports phloem respiration (Pizzio et al., 2015).

The V-ATPase consists of the membrane integral sector $V_{O}$ and the membrane-associated sector $V_{1}$ (Figure 1), which represent the proton translocator and ATPase, respectively. The active enzyme was identified at the TGN/EE and the vacuole and both isoenzymes can be differentiated by the present isoform of VHA-a: In A. thaliana, the vacuolar pump bears either VHA-a2 or VHA-a3, while the TGN-located pump bears VHA-a1 (Dettmer et al., 2006). Other proteins might contribute to the active complex, since interaction with the glycolytic aldolase has been identified, which links the proton pumping to the cellular energy state (Konishi et al., 2004; Schnitzer et al., 2011). The V-ATPase energizes the transport of solutes 
A

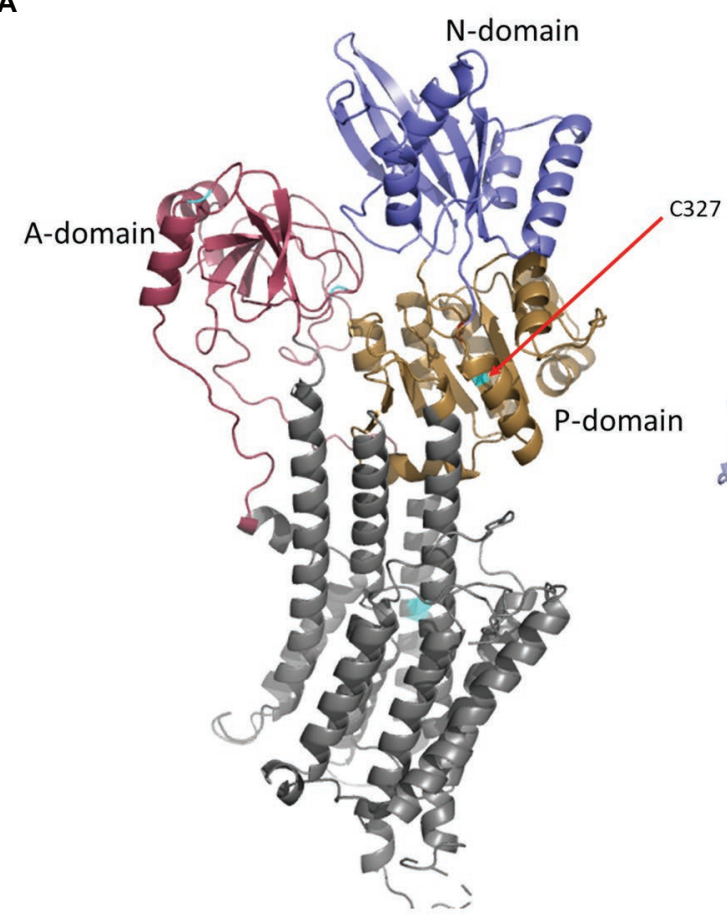

C

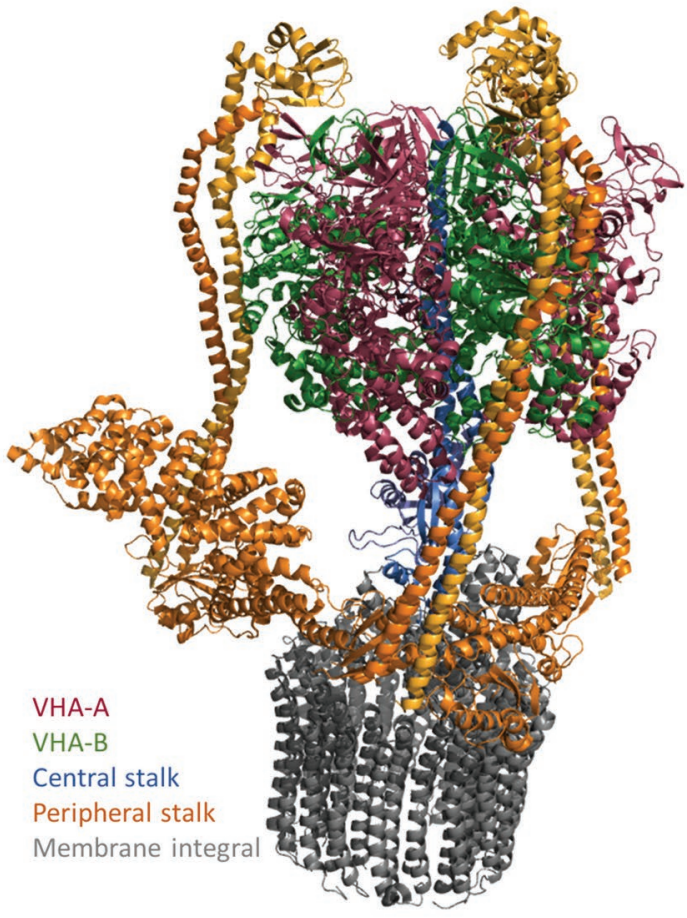

B

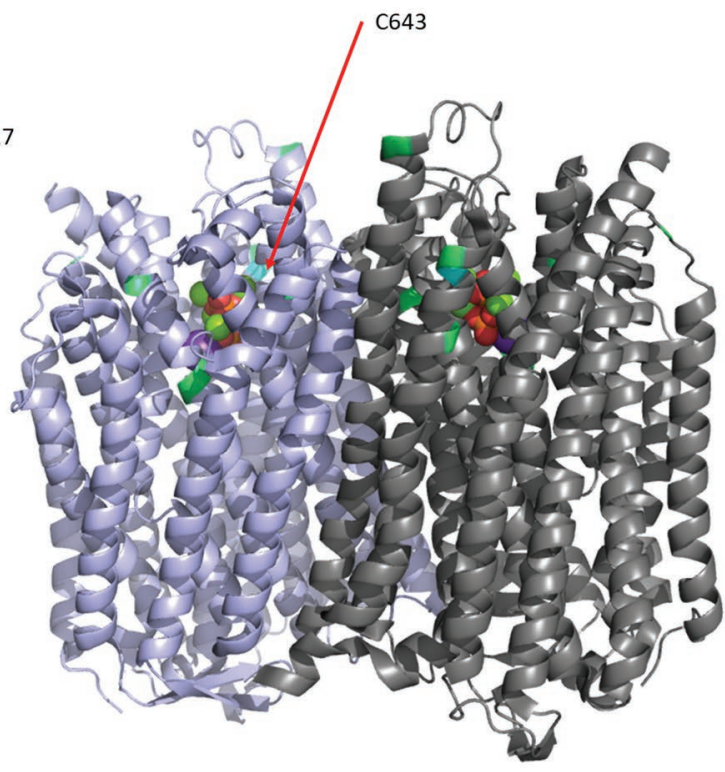

D

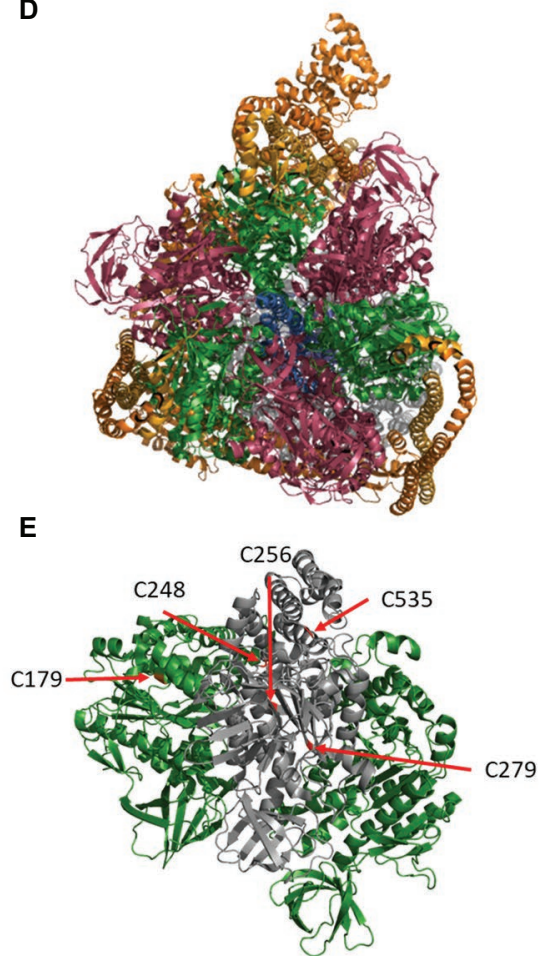

FIGURE 1 | Structures of the proton pumps. The structures of plasma membrane-ATPase (PM-ATPase) AHA2 of Arabidopsis thaliana (A) and vacuolar pyrophosphatase (V-PPase) from Vigna radiata (B) base on the pdb-files 5KSD (Croll and Andersen, 2016; Focht et al., 2017) and 6AFS (Tsai et al., 2019), respectively. (A) The PM-ATPase consists of 10 transmembrane domains and a large cytoplasmic C-terminal domain (Almeida et al., 2017; Nguyen et al., 2020). In detail, the structure of the cytosolic domain can be divided into the actuator- (A-domain), the nucleotide-binding- (N-domain), which is embedded in the phosphorylation domain (P-domain), and a disordered C-terminal region. ATP binds to the nucleotide-binding domain, which in turn moves closer to the phosphorylation domain, thereby forming the catalytic site. Cysteine residues are indicated by cyan coloring. (B) The V-PPase (EC 3.6.1.1) functions as 


\begin{abstract}
FIGURE 1 | homodimeric proton pump of $160 \mathrm{kDa}$ at the tonoplast and acidifies vacuoles, in particular, vacuoles of expanding cells (Smart et al., 1998; Maeshima, 2001). It consists of 16 transmembrane domains, of which six helices are required for proton transport and cytosolic domains form five $\mathrm{Mg}^{2+}$-binding sites in $\mathrm{V}$. radiata (Tsai et al., 2019). The 14-3-3 binding sites (green) and the conserved Cys643 (cyan) are highlighted. One molecule pyrophosphate is bound each monomer and visible as balls in the center. (C) The vacuolar-type ATPase (V-ATPase) consists of the membrane integral sector Vo (VHA-a, VHA-c, VHA-c", VHA-d, and VHA-e) and the membrane associated sector $\mathrm{V}_{1}(\mathrm{VHA}-\mathrm{A}-\mathrm{VHA}-\mathrm{H})$, which represent the proton translocator (gray) and ATPase, respectively (C). Proton transport occurs by rotation of a proteolipid ring formed by multiple copies of VHA-c and a single copy of VHA-c". VHA-a contributes half channels as proton inlet and outlet pipes. The protons have accessed to a conserved glutamate residue of the proteolipids, protonated the amino acid, and become deprotonated after one approximately one turn by a positive barrier charge of VHA-a, which alters the pKa of the glutamate so that the proton is released into the lumen. VHA-d serves as a bearing between the proteolipid ring and the central stalk of $V_{1}$. This central stalk (blue) is formed by VHA-D and VHA-F and transduces the sequence of conformational alterations due to ATP-hydrolysis within three copies of VHA-A into rotation. (C,D) VHA-A (red) and VHA-B (green) form a hexameric head around (red/green) the central stalk (blue) and are anchored to the membrane by three rigid peripheral stalks (each formed by VHA-E and VHA-G heterodimer, orange), which are crosslinked by VHA-C (orange) and VHA-H (orange) and anchored to the membrane via a cytosolic domain of VHA-a, so that VHA-a is essential for proton transport and avoids co-rotation of the head structure. (E) Within VHA-A, Cys256, Cys279, and Cys535 are highly conserved among all eukaryotes, Cys248 is plant-specific and the distance between Cys Cys 256 and Cys 248 is approximately $11 \AA$ and would allow for disulfide formation. VHA-B bears Cys179, which is target of redox modification. The pdb-file 3j9t was used as template (Zhao et al., 2015).
\end{abstract}

into and out of the vacuole together with the V-PPase. Interestingly, lack of the vacuolar isoenzyme is tolerated by the plant cells, as shown by a double knock-out of the vacuolarspecific subunits VHA-a2 and VHA-a3, but knockout of VHA-A, which is essential for all V-ATPases, is embryolethal. It has been postulated that its presence at the TGN/EE is essential due to cell wall components synthesis and transport, while its absence at the tonoplast can be compensated by V-PPase and the TGN-specific isoenzyme (Krebs et al., 2010).

\section{COORDINATION OF TRANSPORT}

In plants, PM-ATPase, V-PPase, and V-ATPase regulate cellular $\mathrm{pH}$ homeostasis in combination with other transporters. Coordination can be achieved by ionic conditions in the cytosol, in particular calcium ions and nitrate, cytosolic $\mathrm{pH}$, nucleotides, malate, kinases, and phosphatases, redox conditions, and membrane potential. Assuming lack of coordination of transport processes at tonoplast and plasma membrane, the cytosolic solute concentration would putatively increase by $150 \mathrm{mM} / \mathrm{min}$ in guard cells during stomata opening (Cubero-Font and de Angeli, 2020).

The uptake of nitrate or ammonia is accompanied by uptake of other ions and results in transient change of the membrane potential of the plasma membrane. Ammonia stimulates the activity of the plasma membrane ATPase (Yamashita et al., 1995). Since the nitrate assimilation is proton-consuming, it might level the proton influx caused by nitrate influx (Feng et al., 2020). Excess of nitrate inhibits V-ATPase activity, and the electrochemical gradient at the plasma membrane enables nitrate efflux in order to balance the cytosolic $\mathrm{pH}$ (Feng et al., 2020). Thus, proton pumping is directly affected by nitrate so that it might contribute to coordination of proton pumps. This can be mediated by the chloride channel family CLC, which is responsible for chloride and nitrate transport. In A. thaliana, the family consists of seven members (CLC-a-g) and locates to the vacuole and the TGN (von der FechtBartenbach et al., 2007). Feng et al. (2020) postulate that $\mathrm{V}$-ATPase and CLC-a co-operate to balance the cytosolic pH, electrical balance also depends on potassium transport. Fine tuning of cytosolic $\mathrm{pH}$ is achieved by Alkali cation/proton antiporters like $\mathrm{Na}^{+} / \mathrm{H}^{+}$-antiporter (NHX) and CHX in response to environmental changes, NHX1 and NHX2 might further be a major source of proton leakage (Sze and Chanroj, 2018).

Within the cytosolic environment, ROS play an important role in both posttranslational modification and, consequently, intracellular signaling. In response to biotic and abiotic stress, ROS and also RNS (reactive nitrogen species) accumulate (Hasanuzzaman et al., 2020). Besides mitochondria, chloroplasts, and peroxisomes, ROS formation also occurs in the apoplastic space by plasma membrane NADPH oxidases [NOXs; or respiratory burst oxidase homologs (RBOHs)], cell wall-associated peroxidases (POXs), and oxalate oxidases (Torres et al., 1998; Kawano, 2003; Mittler et al., 2004; Asada, 2006; Sagi and Fluhr, 2006; Qi et al., 2017). NOXs were shown to be activated by cytosolic acidification to inhibit growth under conditions of acid stress (Bissoli et al., 2020). As the most stable form of ROS, hydrogen peroxide $\left(\mathrm{H}_{2} \mathrm{O}_{2}\right)$ is capable of migrating across biological membranes via aquaporins (Bienert et al., 2006, 2007). $\mathrm{H}_{2} \mathrm{O}_{2}$ can either cause oxidative damage to proteins and DNA or act as a signaling molecule, thereby regulating plant physiological processes (Mittler and Berkowitz, 2001). The sulfur containing amino acids methionine and cysteine are particularly addressed by $\mathrm{H}_{2} \mathrm{O}_{2}$. Redox-based PTMs determine protein activity, binding affinity, localization, protein-interaction, and conformation (Valderrama et al., 2007; Spoel and Loake, 2011; Jacques et al., 2015; Zhang et al., 2020).

In vitro, V-ATPase activity is inhibited upon treatment with $\mathrm{H}_{2} \mathrm{O}_{2}$, nitric oxide, $\mathrm{N}$-ethylmalmeide, iodacetamide, and oxidized glutathionine and thioredoxin (Hager and Biber, 1984; Hager and Lanz, 1989; Dietz et al., 1998; Tavakoli et al., 2001; Seidel et al., 2012). It has recently been demonstrated in cucumber that the plant V-ATPase activity can be fine-tuned by $\mathrm{H}_{2} \mathrm{~S}$ as a counterpart to $\mathrm{H}_{2} \mathrm{O}_{2}$. Plants treated with $\mathrm{H}_{2} \mathrm{~S}$-source $\mathrm{NaHS}$ were upregulated in V-ATPase activity, whereas lowered $\mathrm{H}_{2} \mathrm{~S}$ content reduced V-ATPase activity. This might be due to $\mathrm{H}_{2} \mathrm{~S}$ mediated release of inhibitory disulfide bridges (Kabala et al., 2019). Similarly, PM-ATPase activity was reported to be enhanced by $\mathrm{H}_{2} \mathrm{~S}$ in soy bean roots (Wang et al., 2019).

VHA-A was identified as redox-sensitive subunit (Wang et al,, 2012; Waszczak et al., 2014). In VHA-A, Cys256, Cys279, and Cys535 are highly conserved among all eukaryotes (Seidel et al., 2012). Although, Feng and Forgac (1994) observed 
disulfide bridge formation, the ATP-binding is not affected by disulfide bridge formation within subunit A. Accordingly, the absence of Cys279 or Cys535 residues does not abolish V-ATPase sensitivity toward $\mathrm{H}_{2} \mathrm{O}_{2}, \mathrm{GSSH}$, and GSNO, whereas C256S mutants are mainly insensitive. Taken together, in A. thaliana, Cys256 mediates sensitivity of V-ATPase ATP-hydrolysis toward redox changes, while proton pumping activity is Cys256independently inhibited by $\mathrm{H}_{2} \mathrm{O}_{2}$. Because Cys256, Cys279, and Cys535 could not be demonstrated to be involved in disulfide bridge formation in VHA-A, the close distance of S-sulfenylated Cys248 to Cys256 needs to be taken into account, although Cys248 is only conserved among plants (Figure 1). Grüber et al. (2000) reported the V-ATPase subunit VHA-B of insect midgut undergoing structural alteration upon non-reducing conditions. In VHA-B, only one cysteine (Cys179) is conserved among eukaryotes. Intramolecular disulfide formation has also been reported in barley subunit $\mathrm{E}$ that occurs upon oxidative treatment of V-ATPase in vivo and was stated to be involved in redoxdependent V-ATPase activity changes (Tavakoli et al., 2001). In A. thaliana, subunit VHA-E Cys134 and Cys186 are conserved among plant species, but do not occur in other organisms, suggesting a plant specific function (Tavakoli et al., 2001).

At the plasma membrane, NOX catalyzes electron transfer from NADPH to $\mathrm{O}_{2}$. Thereby, NOX generates apoplastic $\mathrm{O}_{2}{ }^{-}$, but also acidifies the cytosol (Ramsey et al., 2009). In order to counteract cytosolic acidification and to provide $\mathrm{H}^{+}$for apoplastic ROS scavenging processes, PM-ATPase has been proposed to be cooperatively regulated with NOX (Majumdar and $\mathrm{Kar}, 2018)$. Indeed, $\mathrm{H}_{2} \mathrm{O}_{2}$ concentrations up to $50 \mu \mathrm{M}$ promoted PM-ATPase activity in Vigna radiata, whereas higher $\mathrm{H}_{2} \mathrm{O}_{2}$ concentration was inhibitory. Furthermore, in the presence
ROS-scavengers and NOX inhibitors, PM-ATPase activity decreased, supporting the idea of $\mathrm{H}_{2} \mathrm{O}_{2}$-dependent activation of PM-ATPase (Majumdar and Kar, 2018). Involvement of $\mathrm{H}_{2} \mathrm{O}_{2}$ in upregulation of PM-ATPase has also been reported in Populus euphratica callus (Zhang et al., 2007) and in Carex moorcroftii callus (Li et al., 2011). However, plasma membrane $\mathrm{H}^{+}$-ATPase inactivation at higher $\mathrm{H}_{2} \mathrm{O}_{2}$ concentration might occur due to thiol oxidation (Lee et al., 2004; Beffagna et al., 2005; Majumdar and Kar, 2018). Cytosolic pH changes correlate with $\mathrm{H}_{2} \mathrm{O}_{2}$ accumulation; this data suggest PM-ATPase to adjust proton transport dependent on $\mathrm{H}_{2} \mathrm{O}_{2}$ accumulation (Beffagna et al., 2005). Five cysteine residues of AHA1 are conserved among plants (Figure 2), of which Cys327 is located in the cytosolic P-domain. Cys327 is conserved among all P2 and P3 ATPases in eukaryotes, shows a close distance to the phosphorylated aspartate residue and $\mathrm{Mg}^{2+}$-binding site, is redox-sensitive and thereby pointing to a redox regulatory role (Welle et al., 2021).

Redox control of V-PPase is poorly understood. AtAVP1 possesses seven cysteine residues that are conserved among plant species. First evidence of V-PPase being addressed by redox changes in A. thaliana came from (Zhen et al., 1994), who reported irreversible inhibition by N-ethylmaleimide (NEM) and 3-(N-maleimidylpropionyl) biocytin (MPB). Cys643 was shown to be exclusively affected by NEM, thereby inhibiting both PPi hydrolysis and $\mathrm{H}^{+}$translocating activity (Figure 2). Nevertheless, substitution of Cys643 to alanine or serine has not changed total V-PPase activity, suggesting a rather regulatory or even the lack of an important function (Kim et al., 1995).

Proton pumps, potassium-channels, and CLC-proteins are target of phosphorylation. Kinases might act on proteins in different membranes, such as the receptor-like kinase KIN7, which locates

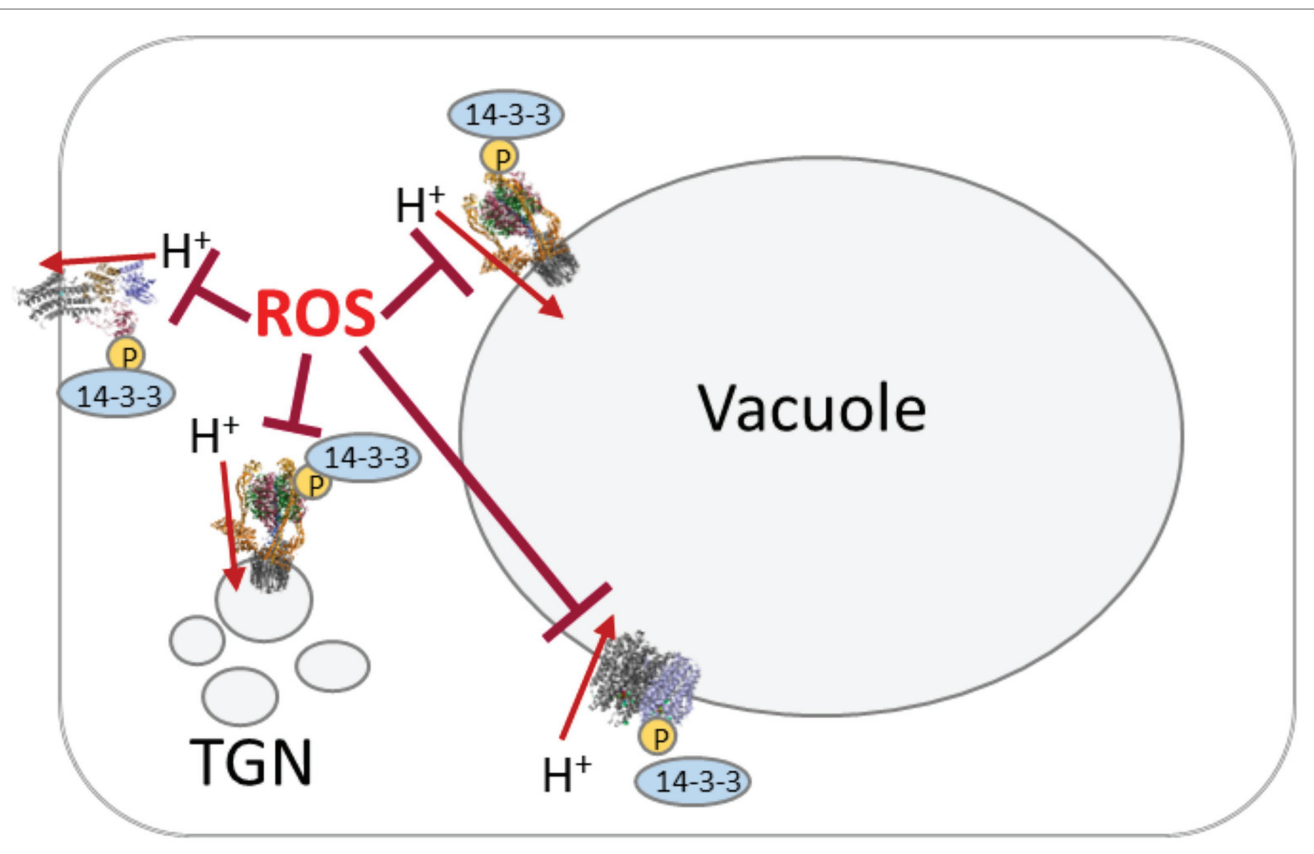

FIGURE 2 | Scheme of proton pumping-coordination by reactive oxygen species (ROS) and phosphorylation/14-3-3 proteins. Proton pumps are target of oxidative inhibition by ROS. The activated state involves phosphorylation by cytosolic kinases ("P" in yellow circle) and subsequent binding of 14-3-3 proteins. 
to the tonoplast and the plasma membrane (Isner et al., 2018; van Kleeff et al., 2018; Subba et al., 2020) or the SOS2/SOS3 complex, which activates cation-proton-antiporters (NHX, CAX), V-ATPase, and PPase (Shabala et al., 2020). Other candidates are MAPKs, which might act on transporters, too (Cubero-Font and de Angeli, 2020). Together with membrane-associated phosphatases they seem to be key players of transport regulation: PP2A dephosphorylates CLC-a (Subba et al., 2020), PP2A-C5 interacts with the vacuolar CLCs $-\mathrm{a},-\mathrm{b},-\mathrm{c}$, and $-\mathrm{g}$ ( $\mathrm{Hu}$ et al., 2017). Inhibition of PP2C.D keeps PM-ATPase active (Spartz et al., 2017), what is in good agreement with auxin-dependent inactivation of PP2C-D1 manner by SMALL AUXIN UP RNA 19 (SAUR19) for regulating AHA1 and AHA2 in A. thaliana (Mangano et al., 2018; Ren et al., 2018). However, the subsequent binding of 14-3-3 proteins to phosphorylated proton pumps might be the real coordinating step (Figure 2). Indeed, Almeida et al. (2017) suggested that all three proton pumps are regulated by one mechanism with 14-3-3 proteins as a good candidate. 14-3-3 proteins act on all three proton pumps, mediating for instance blue light-activation of PM-ATPase and V-ATPase (Assmann et al., 1985; Klychnikov et al., 2007; Hsu et al., 2018; Nguyen et al., 2020). 14-3-3 proteins act as dimers and combining the 13 isoforms in A. thaliana allows for the formation of 91 homoand heterodimers. Isoform-specifity has been analyzed for the V-PPases, where isoforms $\nu, \mu, 0$, and 1 increased the activity and protected against inhibition by high levels of pyrophosphate (Hsu et al., 2018). Besides the high number of putative 14-3-3 dimers, a high number of eight putative binding sites were identified (Figure 1), even binding independent of phosphorylation was observed (Hsu et al., 2018). In case of the PM-ATPase, 14-3-3 proteins bind to the phosphorylated C-terminal domain in an activating manner, preventing the autoinhibitory function of the domain and enabling binding to the RIN4-complex, a negative regulator of plant immunity (Liu et al., 2009; Kaundal et al., 2017). This interaction is terminated by GCN4-mediated degradation of 14-3-3 proteins and RIN4-complex (Kaundal et al., 2017). Binding of 14-3-3 proteins can even result in hyperactive hexamers of PM-ATPase (Nguyen et al., 2020). 14-3-3 proteins also act on GORK, which is phosphorylated by CPK21 and then target of the 14-3-3 isoforms $\lambda$, $\chi$, and $\nu$ (van Kleeff et al., 2018).

\section{REFERENCES}

Almeida, D. M., Oliveira, M. M., and Saibo, N. J. M. (2017). Regulation of $\mathrm{Na}^{+}$and $\mathrm{K}^{+}$homeostasis in plants: towards improved salt stress tolerance in crop plants. Genet. Mol. Biol. 40, 326-345. doi: 10.1590/1678-4685gmb-2016-0106

Appelhagen, I., Nordholt, N., Seidel, T., Spelt, K., Koes, R., Quattrochio, F., et al. (2015). TRANSPARENT TESTA 13 is a tonoplast $\mathrm{P}_{3 \mathrm{~A}}$-ATPase required for vacuolar deposition of proanthocyanidins in Arabidopsis thaliana seeds. Plant J. 82, 840-849. doi: 10.1111/tpj.12854

Asada, K. (2006). Production and scavenging of reactive oxygen species in chloroplasts and their functions. Plant Physiol. 141, 391-396. doi: 10.1104/ pp.106.082040

Assmann, S. M., Simoncini, L., and Schroeder, J. I. (1985). Blue light activates electrogenic ion pumping in guard cell protoplasts of Vicia faba. Nature 318, 285-287. doi: 10.1038/318285a0

Barragán, V., Leidi, E. O., Andrés, Z., Rubio, L., De Luca, A., Fernández, J. A., et al. (2012). Ion exchangers NHX1 and NHX2 mediate active potassium

\section{CONCLUSION}

Though more data are required on some regulatory mechanism, it is plausible that coordinated regulation of plant proton pumps occurs on several levels with respect to the growth conditions. Pathogen-defense likely involves ROS first as messenger and then as defense strategy and requires adjustment of the proton pumps according to the current state (Figure 2). Interestingly, non-protein thiols have been intensively analyzed for their effect on proton pumping, but the knowledge on the impact of protein thiols is still scarce.

Phosphorylation and 14-3-3 proteins mediate a day-night dependency of the proton pumping activity, adjusting for instance nitrate transport and assimilation to the diurnal requirements, besides the direct interaction between nitrate and proton pumps. The number of kinases, phosphatases, and 14-3-3 proteins result in a broad variety of combinations, pointing to high flexibility for adjustments of proton transport and cytosolic redox homeostasis. Finally, yet importantly, the contribution of anion and cation transport is essential for cytosolic pH-stat and maintenance of lumenal conditions and membrane potentials.

\section{AUTHOR CONTRIBUTIONS}

MC and TS have prepared the manuscript. MC focused on redox-regulation. TS focused on the general aspects and 14-3-3 proteins. All authors contributed to the article and approved the submitted version.

\section{FUNDING}

This manuscript has been funded by Bielefeld University.

\section{ACKNOWLEDGMENTS}

We acknowledge support for the publication costs by the Open Access Publication Fund of Bielefeld University.

uptake into vacuoles to regulate cell turgor and stomatal function in Arabidopsis. Plant Cell 24, 1127-1142. doi: 10.1105/tpc.111.095273

Bassil, E., Ohto, M.-A., Esumi, T., Tajima, H., Zhu, Z., Cagnac, O., et al. (2011). The Arabidopsis intracellular $\mathrm{Na}^{+} / \mathrm{H}^{+}$antiporters NHX5 and NHX6 are endosome associated and necessary for plant growth and development. Plant Cell 23, 224-239. doi: 10.1105/tpc.110.079426

Baykov, A. A., Bakuleva, N. P., and Rea, P. A. (1993). Steady-state kinetics of substrate hydrolysis by vacuolar $\mathrm{H}^{+}$-pyrophosphatase. A simple threestate model. Eur. J. Biochem. 217, 755-762. doi: 10.1111/j.1432-1033.1993. tb18303.x

Beffagna, N., Buffoli, B., and Busi, C. (2005). Modulation of reactive oxygen species production during osmotic stress in Arabidopsis thaliana cultured cells: involvement of the plasma membrane $\mathrm{Ca}_{2}{ }^{+}$-ATPase and $\mathrm{H}^{+}$-ATPase. Plant Cell Physiol. 46, 1326-1339. doi: 10.1093/pcp/pci142

Bienert, G. P., Møller, A. L. B., Kristiansen, K. A., Schulz, A., Møller, I. M., Schjoerring, J. K., et al. (2007). Specific aquaporins facilitate the diffusion of hydrogen peroxide across membranes. J. Biol. Chem. 282, 1183-1192. doi: $10.1074 /$ jbc.M603761200 
Bienert, G. P., Schjoerring, J. K., and Jahn, T. P. (2006). Membrane transport of hydrogen peroxide. Biochim. Biophys. Acta 1758, 994-1003. doi: 10.1016/j. bbamem.2006.02.015

Bissoli, G., Muñoz-Bertomeu, J., Bueso, E., Sayas, E., Vilcara, E. A., Felipo, A., et al. (2020). An Arabidopsis mutant over-expressing subtilase SBT4.13 uncovers rhe role of oxidative stress in the inhibition of growth by intracellular acidification. Int. J. Mol. Sci. 21:1173. doi: 10.3390/ijms21031173

Briskin, D. P., and Hanson, J. B. (1992). How does the plant plasma membrane $\mathrm{H}^{+}$-ATPase pump protons? J. Exp. Bot. 43, 269-289. doi: 10.1093/jxb/43.3.269

Croll, T. I., and Andersen, G. R. (2016). Re-evaluation of low-resolution crystal structures via interactive molecular-dynamics flexible fitting (iMDFF): a case study in complement C4. Acta Crystallogr. Sect. F Struct. Biol. Cryst. Commun. 72, 1006-1016. doi: 10.1107/S2059798316012201

Cubero-Font, P., and de Angeli, A. (2020). Connecting vacuolar and plasma membrane transport networks. New Phytol. 229, 755-762. doi: 10.1111/ nph.16983

Dettmer, J., Hong-Hermesdorf, A., Stierhof, Y. D., and Schumacher, K. (2006). Vacuolar $\mathrm{H}^{+}$-ATPase activity is required for endocytic and secretory trafficking in Arabidopsis. Plant Cell 18, 715-730. doi: 10.1105/tpc.105.037978

Dietz, K. J., Heber, U., and Mimura, T. (1998). Modulation of the vacuolar $\mathrm{H}^{+}$-ATPase by adenylates as basis for the transient CO2-dependent acidification of the leaf vacuole upon illumination. Biochim. Biophys. Acta Biomembr. 1373, 87-92. doi: 10.1016/S0005-2736(98)00094-7

Feng, H., Fan, X., Miller, A. J., and Xu, G. (2020). Plant nitrogen uptake and assimilation: regulation of cellular pH homeostasis. J. Exp. Bot. 71, 4380-4392. doi: $10.1093 / \mathrm{jxb} /$ eraa150

Feng, Y., and Forgac, M. (1994). Inhibition of vacuolar $\mathrm{H}^{+}$-ATPase by disulfide bond formation between cysteine 254 and cysteine 532 in subunit A.J. Biol. Chem. 269, 13224-13230. doi: 10.1016/S0021-9258(17)36822-9

Focht, D., Croll, T. I., Pedersen, B. P., and Nissen, P. (2017). Improved model of proton pump crystal structure obtained by interactive molecular dynamics flexible fitting expands the mechanistic model for proton translocation in P-type ATPases. Front. Physiol. 8:202. doi: 10.3389/fphys.2017.00202

Fricke, W. (2017). Water transport and energy. Plant Cell Environ. 40, 977-994. doi: $10.1111 /$ pce. 12848

Geilfus, C.-M. (2017). The pH of the Apoplast: dynamic factor with functional impact under stress. Mol. Plant 10, 1371-1386. doi: 10.1016/j.molp.2017.09.018

Graus, D., Konrad, K. R., Bemm, F., Nebioglu, M. G. P., Lorey, C., Duscha, K., et al. (2018). High V-PPase activity is beneficial under high salt loads, but detrimental without salinity. New Phytol. 219, 1421-1432. doi: 10.1111/nph.15280

Grüber, G., Svergun, D. I., Godovac-Zimmermann, J., Harvey, W. R., Wieczorek, H., and Koch, M. H. (2000). Evidence for major structural changes in the Manduca sexta midgut V1 ATPase due to redox modulation. A small angle X-ray scattering study. J. Biol. Chem. 275, 30082-30087. doi: 10.1074/jbc.M002976200

Hager, A., and Biber, W. (1984). Functional and regulatory properties of $\mathrm{H}^{+}$ pumps at the tonoplast and plasma membranes of Zea mays coleoptiles. Z. Naturforsch. C 39, 927-937. doi: 10.1515/znc-1984-9-1012

Hager, A., and Lanz, C. (1989). Essential sulfhydryl groups in the catalytic center of the tonoplast $\mathrm{H}^{+}$-ATPase from coleoptiles of Zea mays $\mathrm{L}$. as demonstrated by the biotin-streptavidin-peroxidase system. Planta 180, 116-122. doi: 10.1007/BF02411417

Haruta, M., Tan, L. X., Bushey, D. B., Swanson, S. J., and Sussman, M. R. (2018). Environmental and genetic factors regulating localization of the plant plasma membrane $\mathrm{H}^{+}$-ATPase. Plant Physiol. 176, 364-377. doi: 10.1104/ pp.17.01126

Hasanuzzaman, M., Bhuyan, M. H. M. B., Parvin, K., Bhuiyan, T. F., Anee, T. I., Nahar, K., et al. (2020). Regulation of ROS metabolism in plants under environmental stress: a review of recent experimental evidence. Int. J. Mol. Sci. 21:8695. doi: 10.3390/ijms21228695

Hoffmann, R. D., Olsen, L. I., Ezike, C. V., Pedersen, J. T., Manstretta, R., López-Marqués, R. L., et al. (2019). Roles of plasma membrane proton ATPases AHA2 and AHA7 in normal growth of roots and root hairs in Arabidopsis thaliana. Physiol. Plant. 166, 848-861. doi: 10.1111/ppl.12842

Hsu, Y.-D., Huang, Y.-F., Pan, Y.-J., Huang, L.-K., Liao, Y.-Y., Lin, W.-H., et al. (2018). Regulation of $\mathrm{H}+$-pyrophosphatase by 14-3-3 proteins from Arabidopsis thaliana. J. Membr. Biol. 251, 263-276. doi: 10.1007/s00232018-0020-4

Hu, R., Zhu, Y., Wei, J., Chen, J., Shi, H., Shen, G., et al. (2017). Overexpression of PP2A-C5 that encodes the catalytic subunit 5 of protein phosphatase
2A in Arabidopsis confers better root and shoot development under salt conditions. Plant Cell Environ. 40, 150-164. doi: 10.1111/pce.12837

Isner, J. C., Begum, A., Nuehse, T., Hetherington, A. M., and Maathuis, F. J. M. (2018). KIN7 kinase regulates the vacuolar TPK1 $\mathrm{K}^{+}$channel during stomatal closure. Curr. Biol. 28, 466.e4-472.e4. doi: 10.1016/j.cub.2017.12.046

Jacques, S., Ghesquière, B., de Bock, P.-J., Demol, H., Wahni, K., Willems, P., et al. (2015). Protein methionine sulfoxide dynamics in Arabidopsis thaliana under oxidative stress. Mol. Cell. Proteomics 14, 1217-1229. doi: 10.1074/ mcp.M114.043729

Kabala, K., Zboinska, M., Glowiak, D., Reda, M., Jakubowska, D., and Janicka, M. (2019). Interaction between the signaling molecules hydrogen sulfide and hydrogen peroxide and their role in vacuolar $\mathrm{H}^{+}$-ATPase regulation in cadmium-stressed cucumber roots. Physiol. Plant. 166, 688-704. doi: 10.1111/ ppl.12819

Kaundal, A., Ramu, V. S., Oh, S., Lee, S., Pant, B., Lee, H.-K., et al. (2017). General control nonrepressible4 degrades 14-3-3 and the RIN4 complex to regulate stomatal aperture with implications on nonhost disease resistance and drought tolerance. Plant Cell 29, 2233-2248. doi: 10.1105/tpc.17.00070

Kawano, T. (2003). Roles of the reactive oxygen species-generating peroxidase reactions in plant defense and growth induction. Plant Cell Rep. 21, 829-837. doi: 10.1007/s00299-003-0591-Z

Kazmierczak, M., Zhang, X., Chen, B., Mulkey, D. K., Shi, Y., Wagner, P. G., et al. (2013). External pH modulates EAG superfamily $\mathrm{K}^{+}$channels through EAG-specific acidic residues in the voltage sensor. J. Gen. Physiol. 141, 721-735. doi: 10.1085/jgp.201210938

Kesten, C., Gámez-Arjona, F. M., Menna, A., Scholl, S., Dora, S., Huerta, A. I., et al. (2019). Pathogen-induced $\mathrm{pH}$ changes regulate the growth-defense balance in plants. EMBO J. 38:e101822. doi: 10.15252/embj.2019101822

Kim, E. J., Zhen, R. G., and Rea, P. A. (1995). Site-directed mutagenesis of vacuolar $\mathrm{H}^{+}$-pyrophosphatase. Necessity of Cys634 for inhibition by maleimides but not catalysis. J. Biol. Chem. 270, 2630-2635. doi: 10.1074/jbc.270.6.2630

Klychnikov, O. I., Li, K. W., Lill, H., and de Boer, A. H. (2007). The V-ATPase from etiolated barley (Hordeum vulgare L.) shoots is activated by blue light and interacts with 14-3-3 proteins. J. Exp. Bot. 58, 1013-1023. doi: 10.1093/ jxb/erl261

Konishi, H., Yamane, H., Maeshima, M., and Komatsu, S. (2004). Characterization of fructose-bisphosphate aldolase regulated by gibberellin in roots of rice seedling. Plant Mol. Biol. 56, 839-848. doi: 10.1007/s11103-004-5920-2

Krebs, M., Beyhl, D., Goerlich, E., Al-Rasheid, K. A. S., Marten, I., Stierhof, Y.-D., et al. (2010). Arabidopsis V-ATPase activity at the tonoplast is required for efficient nutrient storage but not for sodium accumulation. Proc. Natl. Acad. Sci. U. S. A. 107, 3251-3256. doi: 10.1073/pnas.0913035107

Lee, S. H., Singh, A. P., and Chung, G. C. (2004). Rapid accumulation of hydrogen peroxide in cucumber roots due to exposure to low temperature appears to mediate decreases in water transport. J. Exp. Bot. 55, 1733-1741. doi: 10.1093/jxb/erh189

Li, J., Chen, G., Wang, X., Zhang, Y., Jia, H., and Bi, Y. (2011). Glucose-6phosphate dehydrogenase-dependent hydrogen peroxide production is involved in the regulation of plasma membrane $\mathrm{H}^{+}$-ATPase and $\mathrm{Na}^{+} / \mathrm{H}^{+}$antiporter protein in salt-stressed callus from Carex moorcroftii. Physiol. Plant. 141, 239-250. doi: 10.1111/j.1399-3054.2010.01429.x

Li, Y., Provenzano, S., Bliek, M., Spelt, C., Appelhagen, I., de Faria, L. M., et al. (2016). Evolution of tonoplast P-ATPase transporters involved in vacuolar acidification. New Phytol. 211, 1092-1107. doi: 10.1111/nph.14008

Liu, J., Elmore, J. M., Fuglsang, A. T., Palmgren, M. G., Staskawicz, B. J., and Coaker, G. (2009). RIN4 functions with plasma membrane $\mathrm{H}^{+}$-ATPases to regulate stomatal apertures during pathogen attack. PLoS Biol. 7:e1000139. doi: 10.1371/journal.pbio.1000139

Maeshima, M. (2000). Vacuolar $\mathrm{H}^{+}$-pyrophosphatase. Biochim. Biophys. Acta Biomembr. 1465, 37-51. doi: 10.1016/s0005-2736(00)00130-9

Maeshima, M. (2001). Tonoplast transporters: organization and function. Annu. Rev. Plant Physiol. Plant Mol. Biol. 52, 469-497. doi: 10.1146/annurev. arplant.52.1.469

Majumdar, A., and Kar, R. K. (2018). Congruence between PM H$H^{+}$-ATPase and NADPH oxidase during root growth: a necessary probability. Protoplasma 255, 1129-1137. doi: 10.1007/s00709-018-1217-1

Mangano, S., Martínez Pacheco, J., Marino-Buslje, C., and Estevez, J. M. (2018). How does $\mathrm{pH}$ fit in with oscillating polar growth? Trends Plant Sci. 23, 479-489. doi: 10.1016/j.tplants.2018.02.008 
Martinoia, E. (2018). Vacuolar transporters - companions on a longtime journey. Plant Physiol. 176, 1384-1407. doi: 10.1104/pp.17.01481

Mitsuda, N., Enami, K., Nakata, M., Takeyasu, K., and Sato, M. H. (2001). Novel type Arabidopsis thaliana $\mathrm{H}^{+}$-PPase is localized to the Golgi apparatus. FEBS Lett. 488, 29-33. doi: 10.1016/S0014-5793(00)02400-5

Mittler, R., and Berkowitz, G. (2001). Hydrogen peroxide, a messenger with too many roles? Redox Rep. 6, 69-72. doi: 10.1179/135100001101536067

Mittler, R., Vanderauwera, S., Gollery, M., and van Breusegem, F. (2004). Reactive oxygen gene network of plants. Trends Plant Sci. 9, 490-498. doi: 10.1016/j. tplants.2004.08.009

Morsomme, P., and Boutry, M. (2000). The plant plasma membrane $\mathrm{H}^{+}$-ATPase: structure, function and regulation. Biochim. Biophys. Acta 1465, 1-16. doi: 10.1016/s0005-2736(00)00128-0

Munns, R., Day, D. A., Fricke, W., Watt, M., Arsova, B., Barkla, B. J., et al. (2020). Energy costs of salt tolerance in crop plants. New Phytol. 225, 1072-1090. doi: 10.1111/nph.15864

Nguyen, T. T., Blackburn, M. R., and Sussman, M. R. (2020). Intermolecular and intramolecular interactions of the Arabidopsis plasma membrane proton pump revealed using a mass spectrometry cleavable cross-linker. Biochemist. 59, 2210-2225. doi: 10.1021/acs.biochem.0c00268

Palmgren, M. G. (2001). Plant plasma membrane $\mathrm{H}^{+}$-ATPases: powerhouses for nutrient uptake. Annu. Rev. Plant Physiol. Plant Mol. Biol. 52, 817-845. doi: 10.1146/annurev.arplant.52.1.817

Pizzio, G. A., Paez-Valencia, J., Khadilkar, A. S., Regmi, K., Patron-Soberano, A., Zhang, S., et al. (2015). Arabidopsis type I proton-pumping pyrophosphatase expresses strongly in phloem, where it is required for pyrophosphate metabolism and photosynthate partitioning. Plant Physiol. 167, 1541-1553. doi: 10.1104/ pp.114.254342

Qi, J., Wang, J., Gong, Z., and Zhou, J.-M. (2017). Apoplastic ROS signaling in plant immunity. Curr. Opin. Plant Biol. 38, 92-100. doi: 10.1016/j. pbi.2017.04.022

Ramsey, I. S., Ruchti, E., Kaczmarek, J. S., and Clapham, D. E. (2009). Hv1 proton channels are required for high-level. Proc. Natl. Acad. Sci. 106, 7642-7647. doi: 10.1073/pnas.0902761106

Ren, H., Park, M. Y., Spartz, A. K., Wong, J. H., and Gray, W. M. (2018). A subset of plasma membrane-localized PP2C.D phosphatases negatively regulate SAUR-mediated cell expansion in Arabidopsis. PLoS Genet. 14:e1007455. doi: 10.1371/journal.pgen.1007455

Sagi, M., and Fluhr, R. (2006). Production of reactive oxygen species by plant NADPH oxidases. Plant Physiol. 141, 336-340. doi: 10.1104/pp.106. 078089

Schnitzer, D., Seidel, T., Sander, T., Golldack, D., and Dietz, K.-J. (2011). The cellular energization state affects peripheral stalk stability of plant vacuolar $\mathrm{H}^{+}$-ATPase and impairs vacuolar acidification. Plant Cell Physiol. 52, 946-956. doi: $10.1093 / \mathrm{pcp} / \mathrm{pcr} 044$

Schumacher, K. (2014). pH in the plant endomembrane system an import and export business. Curr. Opin. Plant Biol. 22, 71-76. doi: 10.1016/j.pbi.2014. 09.005

Segami, S., Nakanishi, Y., Sato, M. H., and Maeshima, M. (2010). Quantification, organ-specific accumulation and intracellular localization of type II $\mathrm{H}^{+}$pyrophosphatase in Arabidopsis thaliana. Plant Cell Physiol. 51, 1350-1360. doi: $10.1093 /$ pcp/pcq096

Seidel, T., Scholl, S., Krebs, M., Rienmueller, F., Marten, I., Hedrich, R., et al. (2012). Regulation of the V-type ATPase by redox modulation. Biochem. J. 448, 243-251. doi: 10.1042/BJ20120976

Seidel, T., Siek, M., Marg, B., and Dietz, K.-J. (2013). Energization of vacuolar transport in plant cells and its significance under stress. Int. Rev. Cell Mol. Biol. 304, 57-131. doi: 10.1016/B978-0-12-407696-9.00002-6

Shabala, S., Chen, G., Chen, Z.-H., and Pottosin, I. (2020). The energy cost of the tonoplast futile sodium leak. New Phytol. 225, 1105-1110. doi: 10.1111/ nph.15758

Sivula, T., Salminen, A., Parfenyev, A. N., Pohjanjoki, P., Goldman, A., Cooperman, B. S., et al. (1999). Evolutionary aspects of inorganic pyrophosphatase. FEBS Lett. 454, 75-80. doi: 10.1016/S0014-5793(99) 00779-6

Smart, L. B., Vojdani, F., Maeshima, M., and Wilkins, T. A. (1998). Genes involved in osmoregulation during turgor-driven cell expansion of developing cotton fibers are differentially regulated. Plant Physiol. 116, 1539-1549. doi: 10.1104/pp.116.4.1539
Sondergaard, T. E., Schulz, A., and Palmgren, M. G. (2004). Energization of transport processes in plants. Roles of the plasma membrane $\mathrm{H}^{+}$-ATPase. Plant Physiol. 136, 2475-2482. doi: 10.1104/pp.104.048231

Spartz, A. K., Lor, V. S., Ren, H., Olszewski, N. E., Miller, N. D., Wu, G., et al. (2017). Constitutive Expression of Arabidopsis SMALL AUXIN UP RNA19 (SAUR19) in Tomato Confers Auxin-Independent Hypocotyl Elongation. Plant Physiol. 173, 1453-1462. doi: 10.1104/pp.16.01514

Spoel, S. H., and Loake, G. J. (2011). Redox-based protein modifications: the missing link in plant immune signalling. Curr. Opin. Plant Biol. 14, 358-364. doi: $10.1016 /$ j.pbi.2011.03.007

Subba, A., Tomar, S., Pareek, A., and Singla-Pareek, S. L. (2020). The chloride channels: silently serving the plants. Physiol. Plant. 171, 688-702. doi: 10.1111/ ppl.13240

Sze, H., and Chanroj, S. (2018). Plant endomembrane dynamics: studies of $\mathrm{K}^{+} / \mathrm{H}^{+}$antiporters provide insights on the effects of $\mathrm{pH}$ and ion homeostasis. Plant Physiol. 177, 875-895. doi: 10.1104/pp.18.00142

Taiz, L. (1992). The plant vacuole. J. Exp. Biol. 172, 113-122.

Tavakoli, N., Kluge, C., Golldack, D., Mimura, T., and Dietz, K. J. (2001). Reversible redox control of plant vacuolar $\mathrm{H}^{+}$-ATPase activity is related to disulfide bridge formation in subunit $\mathrm{E}$ as well as subunit A. Plant J. 28, 51-59. doi: 10.1046/j.1365-313X.2001.01130.x

Torres, M. A., Onouchi, H., Hamada, S., Machida, C., Hammond-Kosack, K. E., and Jones, J. D. G. (1998). Six Arabidopsis thaliana homologues of the human respiratory burst oxidase (gp9lphox). Plant J. 14, 365-370. doi: 10.1046/j.1365-313x.1998.00136.x

Tsai, J. Y., Tang, K. Z., Li, K. M., Hsu, B. L., Chiang, Y. W., Goldman, A., et al. (2019). Roles of the hydrophobic gate and exit channel in Vigna radiata pyrophosphatase ion translocation. J. Mol. Biol. 431, 1619-1632. doi: 10.1016/j.jmb.2019.03.009

Valderrama, R., Corpas, F. J., Carreras, A., Fernández-Ocaña, A., Chaki, M., Luque, F., et al. (2007). Nitrosative stress in plants. FEBS Lett. 581, 453-461. doi: $10.1016 /$ j.febslet.2007.01.006

van Kleeff, P. J. M., Gao, J., Mol, S., Zwart, N., Zhang, H., Li, K. W., et al. (2018). The Arabidopsis GORK $\mathrm{K}^{+}-$channel is phosphorylated by calciumdependent protein kinase 21 (CPK21), which in turn is activated by 14-3-3 proteins. Plant Physiol. Biochem. 125, 219-231. doi: 10.1016/j.plaphy. 2018.02.013

von der Fecht-Bartenbach, J., Bogner, M., Krebs, M., Stierhof, Y.-D., Schumacher, K., and Ludewig, U. (2007). Function of the anion transporter AtCLC-d in the trans-Golgi network. Plant J. 50, 466-474. doi: 10.1111/j.1365-313X. 2007.03061.x

Wang, H., Ji, F., Zhang, Y., Hou, J., Liu, W., Huang, J., et al. (2019). Interactions between hydrogen sulphide and nitric oxide regulate two soybean citrate transporters during the alleviation of aluminium toxicity. Plant Cell Environ. 42, 2340-2356. doi: 10.1111/pce.13555

Wang, H., Wang, S., Lu, Y., Alvarez, S., Hicks, L. M., Ge, X., et al. (2012). Proteomic analysis of early-responsive redox-sensitive proteins in Arabidopsis. J. Proteome Res. 11, 412-424. doi: 10.1021/pr200918f

Waszczak, C., Akter, S., Eeckhout, D., Persiau, G., Wahni, K., Bodra, N., et al. (2014). Sulfenome mining in Arabidopsis thaliana. Proc. Natl. Acad. Sci. U. S. A. 111, 11545-11550. doi: 10.1073/pnas.1411607111

Wegner, L. H., and Shabala, S. (2020). Biochemical pH clamp: the forgotten resource in membrane bioenergetics. New Phytol. 225, 37-47. doi: 10.1111/ nph.16094

Welle, M., Pedersen, J. T., Ravnsborg, T., Hayashi, M., Maaß, S., Becher, D., et al. (2021). A conserved, buried cysteine near the P-site is accessible to cysteine modifications and increases ROS stability in the P-type plasma membrane $\mathrm{H}^{+}$-ATPase. Biochem. J. 478, 619-632. doi: 10.1042/BCJ20200559

Yamashita, K., Kasai, M., Ezaki, B., Shibasaka, M., Yamamoto, Y., Matsumoto, H., et al. (1995). Stimulation of $\mathrm{H}^{+}$extrusion and plasma membrane $\mathrm{H}^{+}$-ATPase activity of barley roots by ammonium-treatment. Soil Sci. Plant Nutr. 41, 133-140. doi: 10.1080/00380768.1995.10419566

Zhang, S., Habets, M., Breuninger, H., Dolan, L., Offringa, R., and van Duijn, B. (2020). Evolutionary and functional analysis of a chara plasma membrane $\mathrm{H}^{+}$-ATPase. Front. Plant Sci. 10:1707. doi: 10.3389/fpls.2019.01707

Zhang, F., Wang, Y., Yang, Y., Wu, H., Wang, D., and Liu, J. (2007). Involvement of hydrogen peroxide and nitric oxide in salt resistance in the calluses from Populus euphratica. Plant Cell Environ. 30, 775-785. doi: 10.1111/j.13653040.2007.01667.x 
Zhao, J., Barkla, B. J., Marshall, J., Pittman, J. K., and Hirschi, K. D. (2008). The Arabidopsis cax 3 mutants display altered salt tolerance, $\mathrm{pH}$ sensitivity and reduced plasma membrane $\mathrm{H}^{+}$-ATPase activity. Planta 227, 659-669. doi: $10.1007 /$ s00425-007-0648-2

Zhao, J., Benlekbir, S., and Rubinstein, J. L. (2015). Electron cryomicroscopy observation of rotational states in a eukaryotic V-ATPase. Nature 521, 241-245. doi: 10.1038/nature14365

Zhen, R. G., Kim, E. J., and Rea, P. A. (1994). Localization of cytosolically oriented maleimide-reactive domain of vacuolar $\mathrm{H}^{+}$-pyrophosphatase. J. Biol. Chem. 269, 23342-23350. doi: 10.1016/S0021-9258(17)31659-9
Conflict of Interest: The authors declare that the research was conducted in the absence of any commercial or financial relationships that could be construed as a potential conflict of interest.

Copyright (c) 2021 Cosse and Seidel. This is an open-access article distributed under the terms of the Creative Commons Attribution License (CC BY). The use, distribution or reproduction in other forums is permitted, provided the original author(s) and the copyright owner(s) are credited and that the original publication in this journal is cited, in accordance with accepted academic practice. No use, distribution or reproduction is permitted which does not comply with these terms. 